\title{
Rapid Discrimination of Fish Pathogenic Vibrio and Photobacterium Species by Oligonucleotide DNA Array
}

\author{
Tomomasa Matsuyama*, Takashi Kamaishi and Norihisa Oseko \\ Aquatic Animal Health Division, National Research Institute of Aquaculture, \\ Fisheries Research Agency, Minami-Ise, Mie 516-0193 Japan
}

(Received April 17, 2006)

\begin{abstract}
We developed a low-density oligonucleotide DNA array for the discrimination of 17 Vibrio and 1 Photobacterium species that are pathogenic to aquatic animals. We designed oligonucleotide probes targeting non-coding regions of the intergenic transcribed spacers (ITS) between 16 S and 23S ribosomal DNA. Based on the alignment of ITS sequences obtained from the database and the results in this study, three oligonucleotide probes from a bacterial species were designed and immobilized on a nylon membrane. The ITS regions were PCR-amplified using a pair of universal primers, followed by hybridization of the digoxigenin (DIG)-labeled PCR products to the membrane. Specific signals were produced with alkaline phosphatase-conjugated anti-DIG antibody and chemiluminescent substrate. Although cross hybridization was observed, the patterns from each species were different among the species. This DNA array is useful for a rapid and easy discrimination of Vibrio species. The total process, including PCR amplification, can be carried out within a day. Our method enables a global screening of fish pathogenic Vibrio and Photobacterium species
\end{abstract}

Key words: DNA array, discrimination, Vibrio, Photobacterium

Vibrio species are widely distributed in aquatic environments and many of the species are causative agents of infection in humans and aquatic animals (Buller, 2004). In fish pathology, the identification of Vibrio-like organisms depends first on their growth on a selective medium: thiosulphate citrate bile salt sucrose (TCBS). Generally, further identification depends on their physiological and biochemical characteristics. However, commercial bacterial identification systems based on the characteristics need extreme care to take correct answers, because misidentification by these systems has been reported (Pillot et al., 2002; O'Hara et al., 2003). Alternative serological identification of Vibrio species with polyclonal antisera (Tajima et al., 1987; Martin and Siebeling, 1991; Mutharia et al., 1993; Martinez-Govea et al., 2001) and monoclonal antibodies (Ito and Yokota, 1987; Chen et al., 1992; Sung et al., 1993) has been reported, but the number of detectable species by the serological method is limited. Although some species-specific PCR primers has also been

\footnotetext{
* Corresponding author

E-mail: matsuym@fra.affrc.go.jp
}

reported (Buller, 2004), they are not suitable for exhaustive screening.

DNA array allows the simultaneous screening of a large amount of genes in a short assay time. Because of their usefulness, DNA arrays have been utilized for bacterial identification (Call, 2005). Warsen et al. (2004) developed a DNA array based on 16 S ribosomal RNA gene for the discrimination of fish pathogens. Gonzalez et al. (2004) reported the detection of marine fish pathogenic bacteria using multiplex PCR and DNA microarray. They targeted the genes encoding cytolysin, DNA gyrase B subunit, urease, phospholipase and plasmid borne-loci. Yet, their method is not enough for an exhaustive screening of Vibrio species, because Listonella anguillarum, $V$. parahaemolyticus and $V$. vulnificus has only been targeted.

Intergenic transcribed spacers (ITS) between 16S and 23S rRNA gene were thought to be under less selective constrains and, therefore, to provide higher genetic variation than rRNA gene sequences (Gürtler and Stanisich, 1996). ITS have been utilized to differentiate various bacteria (Gürtler and Stanisich, 1996; Kong et al., 1999; Chen et al., 2005) including Vibrio 
species (Chun et al., 1999; Maeda et al., 2000; Simon et al., 2002). In this study, we utilized species-specific sequences in the ITS non-coding region to design oligonucleotide probes for DNA array for the discrimination of genus Vibrio at the species level.

\section{Materials and Methods}

PCR amplification of ITS non-coding region and sequence analysis

The bacterial strains used in this study are listed in Table 1. Bacteria were cultured on Marine agar 2216 (Difco, USA). Chromosomal DNA was extracted by a method using proteinase $\mathrm{K}$ and phenol-chloroform (Sambrook et al., 1989). The PCR primer pair used for amplification of the ITS non-coding region consisted of VITSF, 5' - wrctctttaacaatttgga-3' (designed based on the consensus sequence found in the box A (Simon et al., 2002) of ITS non-coding region) and VITSR, 5' cgstkagycacttaaccata-3' (designed based on the consensus sequence in 23S rRNA gene). The expression of the primer sequence is based on the IUPAC code. Temperature cycling on an iCycler (Bio-Rad, USA) included an initial denaturation step $\left(94^{\circ} \mathrm{C}\right.$ for 4 $\mathrm{min}), 30$ cycles of core $\mathrm{PCR}$ reaction $\left(30 \mathrm{~s}\right.$ at $94^{\circ} \mathrm{C}, 30 \mathrm{~s}$ at $55^{\circ} \mathrm{C}, 60 \mathrm{~s}$ at $\left.72^{\circ} \mathrm{C}\right)$, and a final elongation step $(7 \mathrm{~min}$ at $72^{\circ} \mathrm{C}$ ). PCR products were cloned into the plasmid vector pDrive (Qiagen, Germany), and amplified for nucleotide sequencing. Sequence was performed using the BigDye Terminator Cycle Sequencing kit (Applied Biosystems, USA) and analyzed in the ABI 377 automated DNA sequencer (Applied Biosystems, USA). The collected sequencing data were aligned using the Genetyx software package (version 6, Genetyx, Japan).

\section{DNA array composed with oligonucleotides}

The sequences of oligonucleotide probes are listed in Table 2. The unique regions to one particular Vibrio and Photobacterium species were identified using the sequence alignment from the sequences obtained in this study and the sequences from a GenBank database. Oligonucleotides were commercially synthesized. Because most Vibrio and Photobacterium species were hardly identified with a single probe, we used a combination of three probes to identify individual species. The positive control probe was designed based on the 5'-end of the 23S rRNA gene sequence. The oligonucleotide probes $(0.1 \mu \mathrm{m}$ in sterilized DW) were transferred onto a positively charged nylon membrane using multi-pin-blotter (Atto, Japan) according to the layout illustrated in Fig. 1. The spotted nylon membrane was baked at $120^{\circ} \mathrm{C}$ for $20 \mathrm{~min}$ and stored at room temperature.
Table 1. Strains used in this study and results of PCR amplification

\begin{tabular}{|c|c|c|}
\hline Species & $\begin{array}{l}\text { Strain numbers } \\
\text { usedfor sequence } \\
\text { analysis and/or } \\
\text { PCR }\end{array}$ & $\begin{array}{l}\text { Results } \\
\text { of PCR } \\
\text { amplifi- } \\
\text { cation }\end{array}$ \\
\hline P. damselae subsp. damselae & АТСС33539 & + \\
\hline P. damselae subsp. piscicida & ATCC17911 & + \\
\hline$V$. alginolyticus & IID950 & + \\
\hline $\begin{array}{l}\text { V. anguillarum } \\
\text { (Listonella anguillarum) }\end{array}$ & NCMB6 & + \\
\hline V. harveyi & $\begin{array}{l}\text { ATCC35084 } \\
\text { HUFP9111 }\end{array}$ & $\begin{array}{l}+ \\
+\end{array}$ \\
\hline V. cholerae & WA1 & + \\
\hline V. fluvialis & IAM14403 & + \\
\hline V. ichthyoenteri & IFO15847 & + \\
\hline V. nigripulchritudo & ATCC27043 & + \\
\hline V. ordalii & ATCC33509 & + \\
\hline V. parahaemolyticus & IFO12711 & + \\
\hline V. pelagius (L. pelagia) & ATCC25916 & + \\
\hline V. penaeicida & $\mathrm{KH} 1$ & + \\
\hline V. salmonicida & NCIMB2262 & + \\
\hline V. splendidus & IAM14411 & + \\
\hline V. tapetis & NCIMB13622 & + \\
\hline V. tubiashii & ATCC19109 & + \\
\hline V. vulnificus & ATCC27562 & + \\
\hline Vibrio sp. * & - & + \\
\hline Aeromonas caviae & JCM1060 & + \\
\hline A. hydrophila & IAM12337 & + \\
\hline A. jandaei & JCM8316 & + \\
\hline A. salmonicida & JCM7874 & - \\
\hline A. sobria & JCM2139 & + \\
\hline Bacillus subtilis & IAM1069 & - \\
\hline Citrobacter freundii & FPC349 & - \\
\hline Edwardsiella ictaluri & JCM1679 & - \\
\hline E. tarda & ATCC15947 & - \\
\hline Escherichia coli & IAM1239 & - \\
\hline E. vulneris & IAM14239 & - \\
\hline Flavobacterium branchiophilum & FPC520 & - \\
\hline F. columnare & ATCC43622 & - \\
\hline F. psychrophilum & NCMB1947 & - \\
\hline Hafnia alvei & JCM1666 & - \\
\hline Klebsiella pneumoniae & IAM12015 & - \\
\hline Lactococcus garvieae & FPC136 & - \\
\hline Micrococcus luteus & IAM1056 & - \\
\hline Nocardia seriolae & TC 258 & - \\
\hline Pseudomonas anguilliseptica & NCMB 1949 & - \\
\hline P. chlororaphis & IAM12354 & - \\
\hline P. fluorescens & IAM12022 & - \\
\hline P. plecoglossicida & ATCC700383 & - \\
\hline P. putida & ATCC12633 & - \\
\hline Serratia marcescens & IAM12142 & - \\
\hline S. plymuthica & IAM13543 & - \\
\hline Staphylococcus aureus & IAM1011 & - \\
\hline S. epidermidis & IAM12012 & - \\
\hline Streptococcus iniae & ATCC29178 & - \\
\hline Tenacibaculum maritimum & ATCC43397 & - \\
\hline Yersinia ruckeri & ATCC29473 & - \\
\hline
\end{tabular}

*: Isolated from diseased striped jack Pseudocaranx dentex (unpublished).

Only extracted genomic DNA exist. 
Table 2. Oligonucleotide probes used for DNA hybridization

\begin{tabular}{|c|c|c|}
\hline Species & Probe & Sequence \\
\hline \multirow[t]{3}{*}{ V. alginolyticus } & A & TGGTGTTTGTCATAAAGACAAACATTGAGAACTTTACAAACAATCTTAAA \\
\hline & B & GATTTTGCCGGACT CAATTTCGAATAATCACT GTAAAAGT GATATT CCCA \\
\hline & C & AACAAGTCACCAAAGTTGTCTCTCATTATTTGAATGAGCGAGAGACATTC \\
\hline V. anguillarum & A & TATCAATACGTTAAACGTATTGATGTTGAGAACTTTTATTTGACAACAAC \\
\hline \multirow[t]{2}{*}{ (L. anguillarum) } & $\mathrm{B}$ & TTGATTTTGCCGGACTCAATTTTGAAAACTTACCGTAGTAAGCT TTCCCA \\
\hline & C & CAGACAAGT CACCAAGGTT GT CTCTCATTATTTGAATGAGCGAGAGACGT \\
\hline V. harveyi & A & TGTATTGGTGTTTGTCATAAAGACAAACATTGAGAACTTTACAAACAAAC \\
\hline \multirow[t]{2}{*}{ (ATCC35084) } & $\mathrm{B}$ & ACTCGATTTTGCCGGACTCAAATTCCAAGAACACTTGAATGT GT T GT ATT \\
\hline & $\mathrm{C}$ & TCAAATCACCAAAGTTGT CT CTCATTATTTGAATGAGCGAGAGACATATC \\
\hline \multirow[t]{3}{*}{ V. cholerae } & A & TGT TGGTGTTTATCTTTCGATAAACATTGAGAACTTTACAAACAACAATA \\
\hline & $\mathrm{B}$ & GATTTTGCCGGACTCAAATTTGAACAAGACCGAAGTCTTATTCGATACCA \\
\hline & C & CTGTTTAAACAACCTAAGTTGTCTCGCGTTTAATTTACATGAGT GCGAGA \\
\hline \multirow[t]{3}{*}{ V. fluvialis } & A & TTTGT TGGT GT AT T CCATTCAGGAATACATT GAGAACTTTACAAACAACA \\
\hline & $\mathrm{B}$ & GT GT GACT GATTTTGCCGGACT CAATTTGAAGACT TACT GAAT CAGTAAG \\
\hline & C & TTGGGTTGCT GT TAAACAACCTAGGT GT CACACATTTATTTTTCATGAGT \\
\hline V. harveyi & A & GGT GT TTGTCGTAAAGACAAACATTGAGAACTTTACAAACAAACTTAAAA \\
\hline \multirow[t]{2}{*}{ (HUFP9111) } & $\mathrm{B}$ & The same sequence as $V$. harveyi (ATCC35084). \\
\hline & C & ATGAACAAGT CACCAAAGTTGTCTGCAATTTTTATACATGATGCAGACTC \\
\hline \multirow[t]{3}{*}{ V. ichthyoenteri } & A & TTTTTGGTGTTTACCTTAAAGGTAAACATTGAGAACTTTTTTCGATAACA \\
\hline & B & АTTTTGCCGGACTCAATTTCGAATAATCATCATAAATGATGATATTGCCA \\
\hline & $\mathrm{C}$ & TTTCGTTAAACAACCAAGTTGTCTCTCTATTTGATGAGTGAGAGACGTTC \\
\hline \multirow[t]{3}{*}{ V. nigripulchritudo } & A & GT TGGT ACCTAAAACACAGTTTTAGGATTTGAGAACTTTTAATTGAATAACAACGCTTAT \\
\hline & $\mathrm{B}$ & AAGAGGTCTTGTATGTTCAAACAACCAAGGTTTGT GTCTCTCATTATTGA \\
\hline & C & AGAGACATTCGATTTTGCCGGACTCAAATATAAACATCACAAGGATGTTT \\
\hline \multirow[t]{3}{*}{ V. ordalii } & A & ATATTGGTGTTTGTCATCAAGACAAGCATTGAGAACTTTACAAACAACAA \\
\hline & $\mathrm{B}$ & CGGACTCAATTTTTСTTCTCСCTTACTTTAAAAAAGTAAGACAAAAGCCA \\
\hline & C & CGAATCTTGAGGAT GTAGTTAAACAACCAAAGTTGTCTGCAATTATTTAA \\
\hline \multirow[t]{3}{*}{ V. parahaemolyticus } & A & GTTTTGTCAGCTTTCCAAATTGTTAAAGAGCTATGTTAGCTATGTTAGCT \\
\hline & B & СTCAAATTCCAAGAACACTTGAATGTGTTATTTTGGTGTTTGTCTTAAAG \\
\hline & C & The same sequence as $V$. harveyi (HUFP9111)-C. \\
\hline V. pelagius & A & TTTACTGTTCTTAATAAATAAGAGCAGATAAACATTGAGAACTTTTAATT \\
\hline \multirow[t]{2}{*}{ (L. pelagia) } & B & GT GTTTGCCGGACT CAATGGT GAATCAATGTAAACATTGATTCGAATACA \\
\hline & C & GTAAACAACCAAGGTTTTTGGTTGTAACAAGAAGGGTTAATTCTTATTAC \\
\hline \multirow[t]{3}{*}{ V. penaeicida } & A & ACCTAAATGAACAAGTCATCTAGGATTTGAGAACTTTTAATTTGAATAAC \\
\hline & $\mathrm{B}$ & GGGTTTTCACGAAAGT GAAAACATATTTGAGT CCGGCAAAAT CGAAGTGT \\
\hline & $\mathrm{C}$ & AACAACCAAGGTTTATCGTTGTCTCTTTATTATGAGCGAGACAACACTTC \\
\hline \multirow[t]{3}{*}{ V. salmonicida } & A & TAACTTAATTACAGCCTGAGCTGTTTTGTTTTACTTTTAAAAAGTAAAGATAAATTAAGC \\
\hline & B & CGCCGGATTCAAAATACAAGAACACTTGAATGTGTTTTTAATTTGTTTAT \\
\hline & $\mathrm{C}$ & GGACGTTTGCTTTCACTTTTCAAAAATGAAGACAAAACAGCAACCAAGGT \\
\hline \multirow[t]{3}{*}{ V. splendidus } & A & TTTATCCAAAGGATAAACATTGAGAACTTTTAATTTGATTAACTCTTAGA \\
\hline & $\mathrm{B}$ & GTGTTTGCCGGACTCAATGTGATTCAAATTAGATTTGAATCGAATACAAG \\
\hline & C & TAATGTATGGCAACTAACCAAGGTTTTTGGTTGTAATAAGAAGGGTTAGT \\
\hline \multirow[t]{3}{*}{ V. tapetis } & A & GTCATAGGATTTGAGAACTTTTAAATTTGAATAACAACTAATCACAGTCG \\
\hline & B & TATGTTTTCATTCGCATGAAAACCCAAGAACACTTGAATGT GT GTTGGTA \\
\hline & C & АTGTATGGCAAACAACCAAGGTTGTCTCTCTATTTTATGAGTGAGAGACG \\
\hline \multirow[t]{3}{*}{ V. tubiashii } & A & AATTCATAGAATTAGGATTTGAGAACTTTTAATTTGAATAACAACGCATCTCAAAGAGAT \\
\hline & $\mathrm{B}$ & ATACATGTGCAGACACGATTTTGCCGGACTCAAATATTAAACATCGCAAG \\
\hline & C & СTCTGTTTAAACAACCAAAGTTGTCTGCATTTTTATACATGTGCAGACAC \\
\hline \multirow[t]{3}{*}{ V. vulnificus } & A & TGTTGGTGTTTGTCATAAAGACAAACATTGAGAACTTTACAAACAACAAT \\
\hline & $\mathrm{B}$ & GATTTTGCCGGACTCAATTTCGAATAGTCACTTAACAGTGACTATTCCCA \\
\hline & C & TTAAACAACCAAAGTTGCTATCTCATTATTTGAATGAGCGAGATAGCGTT \\
\hline \multirow[t]{3}{*}{ P. damselae } & A & GAGAACTCGTTTTTATCTTTCGATAAAAACTTAAAATAAATCAATCATTCGATTGAATTT \\
\hline & $\mathrm{B}$ & GCCGGACTCACTATTTGCTTTCACTTTTAAAAAGT GAAGACAAAAAATAC \\
\hline & C & TTCGTATGTTCAAACAACCAAGGTTGTCTATCTGAGTTGTGATAGACGTT \\
\hline Vibrio sp. & A & GT GTTTACAACTCATGAAAATTCATGAAAAGT AAACTTGAGAACTTT TAATAAAAATTGA \\
\hline & $\mathrm{B}$ & AATCAAACAACCAAAGT TGTCTCTCATTAAATTTTTCATGAGCGAGAGAC \\
\hline & $\mathrm{C}$ & TTTGCTTGCTACTTTTCACTTATGCTGCGTTAGCTTATAAATTTGCTTGG \\
\hline Positive control & & TGCCAAGGCAT CCACCGTGTACGCTTAGT CACTTAACCATACAACCCGAA \\
\hline
\end{tabular}


$\begin{array}{llllll}\mathbf{A} & \mathbf{B} & \mathbf{C} & \mathbf{A} & \mathbf{B} & \mathbf{C}\end{array}$

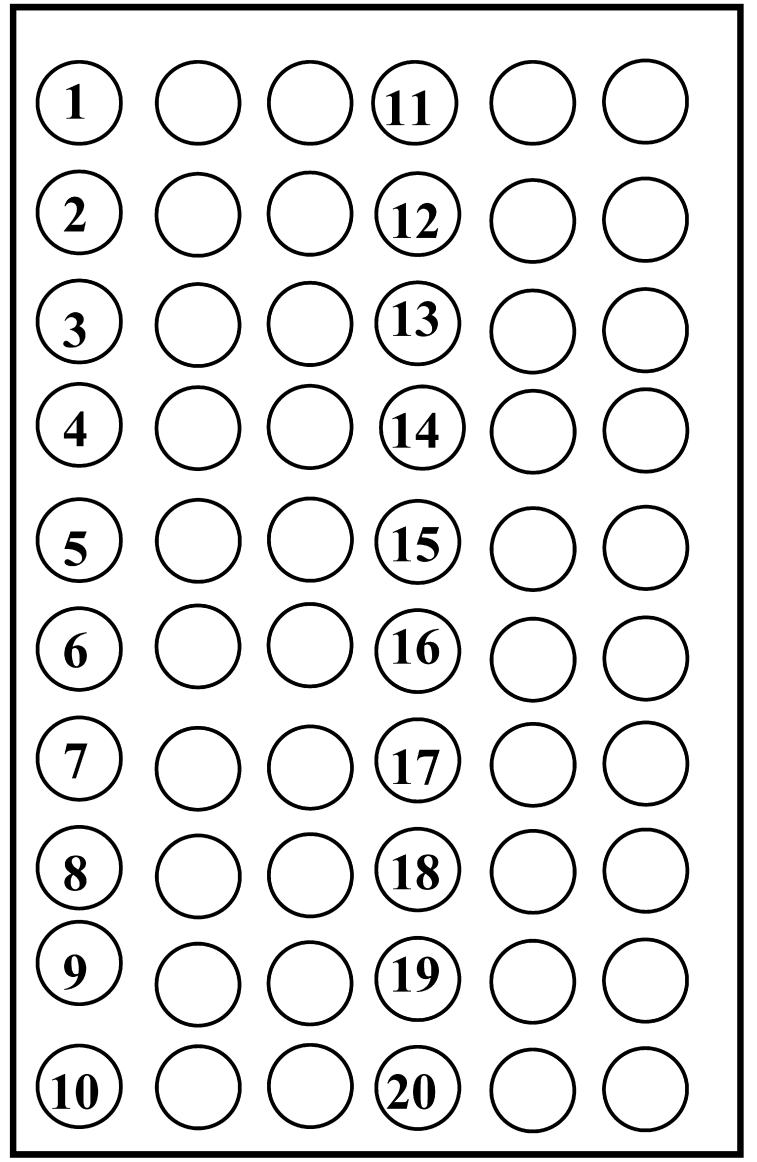

Fig. 1. Positions of Vibrio and Photobacterium-specific oligonucleotides on the DNA array. Spots 1: $V$. alginolyticus, 2: V. anguillarum, 3: V. harveyi (ATCC35084), 4: V. cholerae, 5: V. fluvialis, 6: V. harveyi (HUFP9111), 7: V. ichthyoenteri, 8: V. nigripulchritudo, 9: V. ordalii, 10: V. parahaemolyticus, 11: V. pelagius, 12: $V$. penaeicida, 13: $V$. salmonicida, 14: V. splendidus, 15: V. tapetis, 16: V. tubiashii, 17: V. vulnificus, 18: $P$. damselae, 19: Vibrio sp., 20: positive control.

labeled with digoxigenin (DIG) during PCR amplification. The PCR mixture $(10 \mu \mathrm{L})$ contains DIG-UTP (Roche Diagnostics, Switzerland), Taq DNA polymerase (Takara, Japan), the primers (VITSF and VITSR), buffer and sample DNA. PCR was performed as described above to incorporate DIG into PCR amplicons. Hybridization was performed as follows: A $0.5 \mu \mathrm{L}$ of denatured DIG-labeled PCR product in $500 \mu \mathrm{L}$ of hybridization buffer $(5 \times$ SSC containing $0.1 \% \mathrm{~N}$ lauroylsarcosine, $1 \%$ blocking reagent, $0.02 \%$ SDS and $20 \%$ formamide) was incubated with DNA array at $42^{\circ} \mathrm{C}$ for $2 \mathrm{~h}$. Hybiridization temperature and formamide concentration to obtain high signal intensity was determined in the preliminary examination (data not shown). The membrane was washed 3 times for 5 min each with $2 \times$ SSC $-0.1 \%$ SDS, followed by 5 times for 10 min each with $0.1 \times$ SSC- $0.1 \%$ SDS at room temperature. The membrane was then processed with alkaline phosphatase-conjugated anti-DIG antibody (Roche Diagnostics, Switzerland). Signals were produced with the chemiluminescent substrate CDP-Star (Amersham Biosciences, USA). To detect the signal, instant films were exposed for 1 to 5 minutes to the arrays using an $\mathrm{ECL}$ Mini-Camera (Amersham Biosciences, USA).

\section{Diagnosis using oligonucleotide DNA array}

Ayu (Plecoglossus altivelis), which were suspected of being infected with Vibrio organisms, were diagnosed using oligonucleotide DNA array. Bacteria were isolated from the diseased fish on brain heart infusion agar (Difco) with $1.5 \% \mathrm{NaCl}$. DNA was extracted from the isolated bacterium and the spleen of the fish, and then subjected to oligonucleotide DNA array analysis. API $20 E$ strip (bioMerieux, France) was used to identify the biochemical characteristics of the isolated bacterium.

\section{Results}

PCR amplification of the ITS non-coding region and sequence analysis

Our newly designed PCR primers amplified the ITS non-coding region from all Vibrio and Photobacterium strains analyzed in this study (Table 1). However, no amplicons were obtained from non-Vibrio and nonPhotobacterium specimens, except for $A$. caviae, A. hydrophila, A. jandaei and A. sobria. The amplified segment had a length of 240 to $431 \mathrm{bp}$ and included the 5' end of the 23S rRNA gene sequence. The nucleotide sequence data obtained in this study appear in the GenBank database under accession numbers AB255703 to AB255738. Because differences were seen in the ITS sequences of two strains of $V$. harveyi ATCC35084 and HUFP9111, oligonucleotide probes were designed to each strains.

\section{Hybridization with DNA array}

Fig. 2 shows the prototypes of hybridization images. Number of strains applied to hybridization was shown in Table 3. Although the cross hybridization was observed, all of the tested strains reacted with the corresponding 3 spots and positive controls. The profiles obtained from each species were reproducible and different among the species. $V$. nigripulchritudo, $V$. penaeicida and $V$. vulnificus also hybridized with the three spots corresponding to the $V$. tapetis, $V$. pelagius and $V$. alginolyticus respectively. Among 18 species, $V$. alginolyticus, $V$. harveyi and $V$. parahaemolyticus displayed a similar hybridization image. Aeromonas species were weakly hybridized only to the positive control spots. 

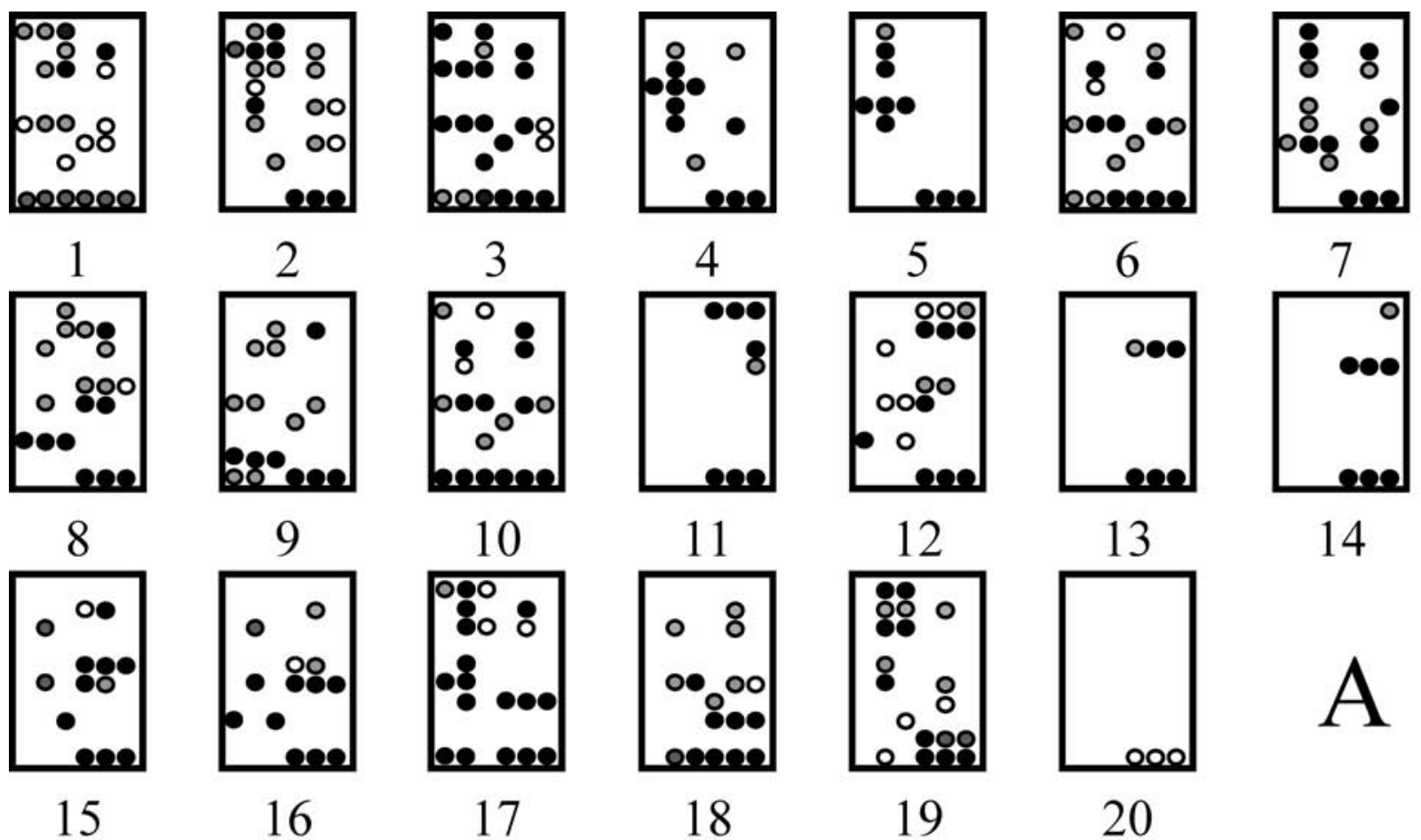

15

16

17

18

19

14

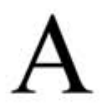

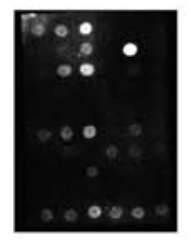

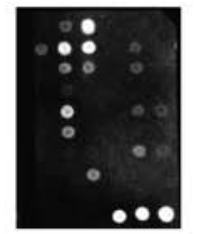

2

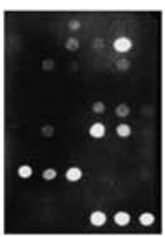

8

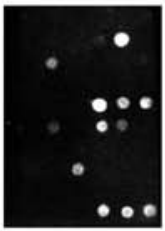

15

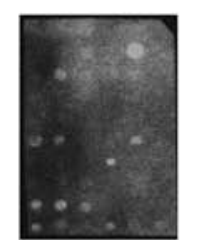

9

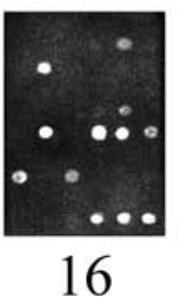

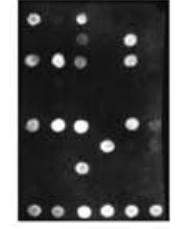

3

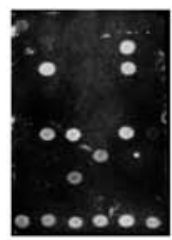

10

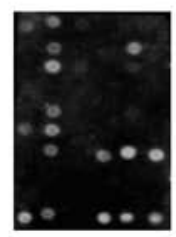

17

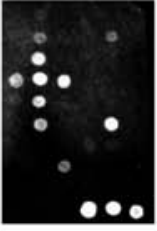

4

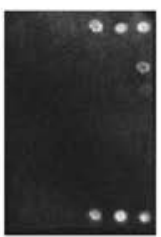

11

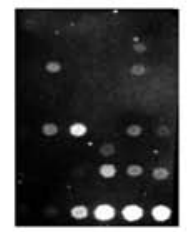

18

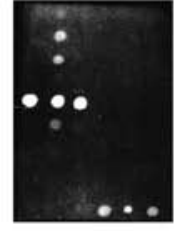

5

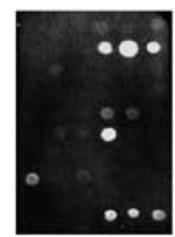

12

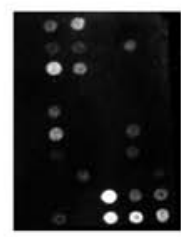

19
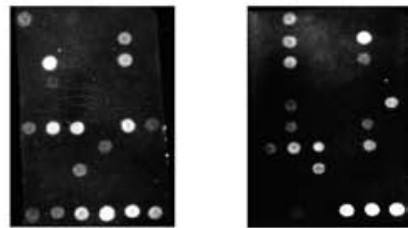

6

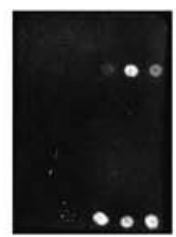

13

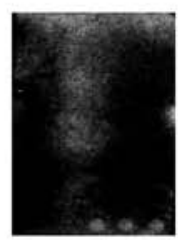

20

Fig. 2. Hybridization images (A) and photographs (B) of 17 Vibrio, 1 Photobacterium and 1 Aeromonas species to the oligonucleotide DNA arrays. Black circle: strong reaction, gray circle: medium reaction, white circle: weak reaction. Image and photograph 1: V. alginolyticus, 2: V. anguillarum, 3: V. harveyi (ATCC35084), 4: V. cholerae, 5: V. fluvialis, 6: V. harveyi (HUFP9111), 7: V. ichthyoenteri, 8: V. nigripulchritudo, 9: V. ordalii, 10: V. parahaemolyticus, 11: V. pelagius, 12: V. penaeicida, 13: V. salmonicida, 14: V. splendidus, 15: V. tapetis, 16: V. tubiashii, 17: V. vulnificus, 18: P. damselae, 19: Vibrio sp., 20 : A. jandaei. 
Table 3. Number of strains applied for hybridization

\begin{tabular}{lc}
\hline \multicolumn{1}{c}{ Species } & Number of strains \\
\hline P. damselae subsp. damselae & 2 \\
P. damselae subsp. piscicida & 2 \\
V. alginolyticus & 1 \\
V. anguillarum (Listonella anguillarum) & 13 \\
V. harveyi & 3 \\
V. cholerae & 2 \\
V. fluvialis & 1 \\
V. ichthyoenteri & 2 \\
V. nigripulchritudo & 1 \\
V. ordalii & 1 \\
V. parahaemolyticus & 1 \\
V. pelagius (L. pelagia) & 1 \\
V. penaeicida & 1 \\
V. salmonicida & 1 \\
V. splendidus & 1 \\
V. tapetis & 1 \\
V. tubiashii & 1 \\
V. vulnificus & 4 \\
Vibrio sp.* & 1 \\
Aeromonas caviae & 1 \\
A. hydrophila & 1 \\
A. jandaei & 1 \\
A. salmonicida & 1 \\
A. sobria & 1 \\
. Isolated fom & 1 \\
\end{tabular}

*: Isolated from diseased striped jack Pseudocaranx dentex (unpublished).

\section{Diagnosis using oligonucleotide DNA array}

Both hybridization images obtained from extracted DNA from the isolated bacteria and the spleen of infected fish represented signals at the three spots corresponding to $V$. anguillarum as well as the hybridization image that obtained from the type strain of the bacterium (Fig. 3). The bacteria isolated from the fish were also identified as $V$. anguillarum from their biochemical characteristics (data not shown).

\section{Discussion}

In this study, we developed a low-density microarray for the rapid discrimination of Vibrio and Photobacterium pathogens. Among 18 species tested in this study, 12 species: $V$. anguillarum, $V$. cholerae, $V$. fluvialis, $V$. ichthyoenteri, V. ordalii, V. pelagius, V. salmonicida, $V$. splendidus, V. tapetis, V. tubiashii, $P$. damselae and Vibrio sp. isolated from diseased striped jack were clearly discriminated by hybridizing with the three spots corresponding to each species. On the contrary, $V$. nigripulchritudo, $V$. penaeicida and $V$. vulnificus also hybridized with the three spots corresponding to the $V$. tapetis, $V$. pelagius and $V$. alginolyticus respectively. However, reverse was not happened, i. e. V. tapetis, $V$. pelagius and $V$. alginolyticus was not hybridized with the three spots corresponding to the $V$. nigripulchritudo, $V$. penaeicida and $V$. vulnificus. Different patterns of cross-hybridization to other species make it possible to distinguish these species. $V$. alginolyticus, $V$. harveyi and $V$. parahaemolyticus displayed similar hybridization images. The similarity of hybridization images was predictable, since three species have similar ITS sequences. Close relationship between these three species has been reported (Kita-Tsukamoto et al., 1993). Therefore, biochemical tests or species-specific PCR (Venkateswaran et al., 1998; Kim et al., 1999; Pillot et al., 2002; Oakey et al., 2003; Conejero and Hedreyda 2004; Di Pinto et al., 2005) should be used to differentiate these three species.
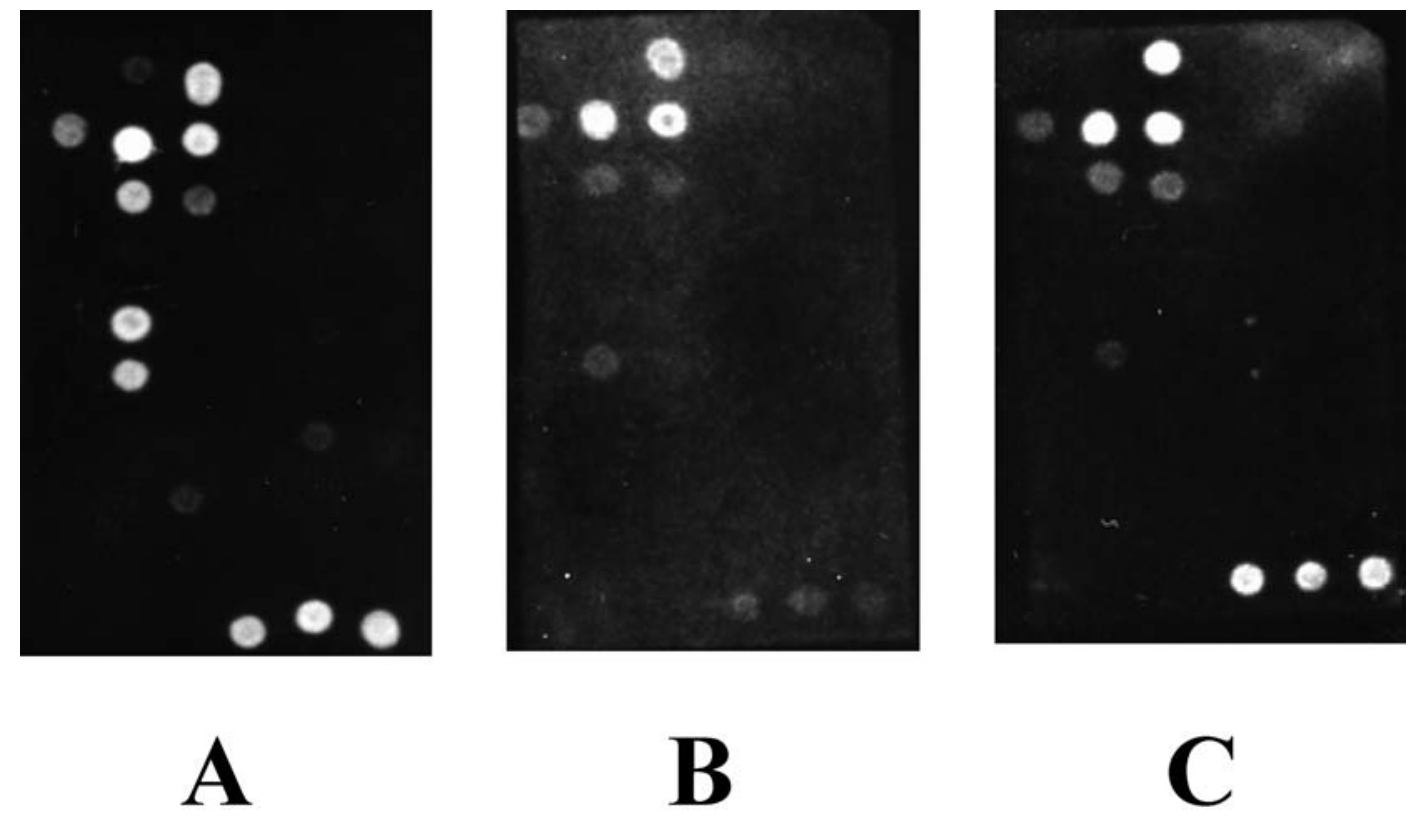

Fig. 3. Hybridization results obtained from DNA extracted from isolated bacteria (A), spleen of infected fish (B) and $V$. anguillarum type strain NCMB $6(C)$. 
Because of their high variability and ease of PCR amplification, we targeted the ITS non-coding region for the discrimination of Vibrio species. It has been reported that the ITS regions shows larger variations than rRNA gene (Gürtler and Stanisich, 1996), which allows designing species-specific probes to distinguish closely related bacterial species. Usage of ITS for microarray-based bacterial identification has additional advantages, because this region is surrounded by conserved genomic regions and can be easily PCR-amplified from a broad spectrum of bacteria using universal primers. The method consisted of PCR amplification of the ITS non-coding region using a pair of universal primers, followed by hybridization of the DIG-labeled PCR products to a panel of oligonucleotides immobilized on a nylon membrane. This method enabled the identification of Vibrio and Photobacterium at the species level within a day including the PCR amplification step. Warsen et al. (2004) developed a DNA array based on $16 \mathrm{~S}$ ribosomal RNA gene for the discrimination of fish pathogens. By this method, 15 fish pathogens were simultaneously detectable, but only $V$. salmonicida was included in the experiment. The poor variation in $16 \mathrm{~S}$ rRNA gene sequences among Vibrio species makes identification at the species level by 16S rRNA gene-targeted hybridization difficult. Gonzalez et al. (2004) reported the detection of marine fish pathogenic bacteria including Vibrio and Photobacterium species using multiplex PCR and DNA microarray. They targeted the genes coding cytolysin, DNA gyrase B subunit, urease, phospholipase and plasmid. Five fish pathogens ( $V$. vulnificus, $V$. anguillarum, $P$. damselae subsp. damselae, $V$. parahaemolyticus and $A$. salmonicida subsp. salmonicida) can be detected by their method. Our method has greatly increased the number of species that can be detected.

Without culture-based techniques, $V$. anguillarum was directly detected from infected ayu. In the case of diagnosis of infected juvenile fish, from which it is usually difficult to isolate the causative agent without contamination, our method is more useful than a classic culture-based method. Unfortunately, because of cross-hybridization, samples with multi-Vibrio infections or from sites containing multiple Vibrio species cannot be directly analyzed by our method. On the other hand, false-positive reactions from multiple infection or contamination of non-Vibrio and non-Photobacterium bacteria can be eliminated by using our newly designed PCR primer pair. Because of their high specificity, no PCR product was obtained from non-Vibrio and nonPhotobacterium specimens, except for some species belonging to the genus Aeromonas. However, amplicons obtained from Aeromonas species were not hybridized with any oligonucleotide except positive controls.

Differences were seen in the ITS sequences of two strains of $V$. harveyi ATCC35084 and HUFP9111.
Intraspecific variations of the ITS sequence might exist in other Vibrio species. In such case, the intraspecific variation may lead to a false negative result. False positive results may also derive from the samples that are not listed under coverage but share the same sequence identity within the probe region. In fact, two distinct species $V$. cholerae and $V$. mimicus cannot be distinguished, because the ITS sequences for the two species are very similar (Chun et al., 1999). When using the method described here, care must be taken at the points described above for the species identification. Our data is insufficient to proof the identification accuracy. More number of strains should be tested to confirm the accuracy of our method. Nevertheless, if un-detectable species or strains were found, the assay can be extended by adding specific oligonucleotide probes to the array to identify more microorganisms.

In conclusion, our method is useful for a rapid and easy discrimination of Vibrio species. The total process, including PCR amplification, can be carried out within a day. Our method enables a global screening of Vibrio and Photobacterium species without special techniques and equipment.

\section{Acknowledgements}

Support for this research was provided by research project for utilizing advanced technologies in agriculture, forestry and fisheries from the Ministry of Agriculture, Forestry and Fisheries of Japan.

\section{References}

Buller, N. B. (2004): Bacteria from fish and other aquatic animals: A practical identification manual. CABI Publishing, UK., $361 \mathrm{p}$.

Call, D. R. (2005): Challenges and opportunities for pathogen detection using DNA microarrays. Crit. Rev. Microbiol., 31, 91-99.

Chen, D., P. J. Hanna, K. Altmann, A. Smith, P. Moon and L. S. Hammond (1992): Development of monoclonal antibodies that identify Vibrio species commonly isolated from infections of humans, fish, and shellfish. Appl. Env. Microbiol., 58, 3694-3700.

Chen, C. C., L. J. Teng, S. Kaiung and T. C. Chang (2005): Identification of clinically relevant viridans streptococci by an oligonucleotide array. J. Clin. Microbiol., 43, 15151521.

Chun, J., A. Huq and R. R. Colwell (1999): Analysis of 16S23S rRNA intergenic spacer regions of Vibrio choleae and Vibrio mimicus. Appl. Environ. Microbiol., 65, 2202-2208.

Conejero M. J. and C. T. Hedreyda (2004): PCR detection of hemolysin (vhh) gene in Vibrio harveyi. J. Gen. Appl. Microbiol., 50, 137-142.

Di Pinto, A., G. Ciccarese, G. Tantillo, D. Catalano and V. T. Forte (2005): A collagenase-targeted multiplex PCR assay for identification of Vibrio alginolyticus, Vibrio cholerae, and Vibrio parahaemolyticus. J. Food. Prot., 68, 150-153.

Gonzalez, S. F., M. J. Krug, M. E. Nielsen, Y. Santos and D. R. Call (2004): Simultaneous detection of marine fish patho- 
gens by using multiplex PCR and a DNA microarray. J. Clin. Microbiol., 42, 1414-1419.

Gürtler, V. and V. A. Stanisich (1996): New approaches to typing and identification of bacteria using the 16S-23S rDNA spacer region. Microbiol., 142, 3-16.

Ito, T. and T. Yokota. (1987): Different types of monoclonal antibodies to Ogawa-specific and gropup-specific antigens of Vibrio cholerae O1. J. Clin. Microbiol., 25, 2289-2295.

Kim, Y. B., J. Okuda, C. Matsumoto, N. Takahashi, S. Hashimoto and M. Nishibuchi (1999): Identification of Vibrio parahaemolyticus strains at the species level by PCR targeted to the toxR gene. J. Clin. Microbiol., 37, 11731177.

Kita-Tsukamoto, K, H. Oyaizu, K. Nanba and U. Simidu (1993): Phylogenetic relationships of marine bacteria, mainly members of the family Vibrionaceae, determined on the basis of 16S rRNA sequences. Int. J Syst. Bacteriol., 43, 8-19.

Kong, R. Y. C., A. Pelling, C. L. So and R. S. S. Wu, (1999): Identification of oligonucleotide primers targeted at the 16S-23S rDNA intergenic spacers for genus- and speciesspecific detection of Aeromonads. Mar. Pollut. Bull., 38, 802-808

Maeda, T., N. Takada, M. Furushita and T. Shiba, (2000): Structural variation in the 16S-23S rRNA intergenic spacers of Vibrio parahaemolyticus. FEMS Microbiol. Lett., 192, 7377.

Martin, S. J. and R. J. Siebeling (1991): Identification of Vibrio vulnificus $O$ serovars with antilipopolysaccharide monoclonal antibody. J Clin Microbiol., 29, 1684-1688.

Martinez-Govea, A., J. Ambrosio, L. Gutierrez-Cogco and A Flisser (2001): Identification and strain differentiation of Vibrio cholerae by using polyclonal antibodies against outer membrane proteins. Clin Diagn Lab Immunol., 8, 768771.

Mutharia, L. W., B. T. Raymond, T. R. Dekievit and R. M. Stevenson (1993): Antibody specificities of polyclonal rabbit and rainbow trout antisera against Vibrio ordalii and serotype 0:2 strains of Vibrio anguillarum. Can $J$ Microbiol., 39, 492-499.
Oakey, H. J., N. Levy, D. G. Bourne, B. Cullen and A. Thomas (2003): The use of PCR to aid in the rapid identification of Vibrio harveyi isolates. J Appl Microbiol., 95, 1293-1303.

O'hara, C. M., E. G. Sowers, C. A. Bopp, S. B. Duda and N. A. Strockbine (2003): Accuracy of six commercially available systems for identification of members of the family Vibrionae. J. Clin. Microbiol., 41, 5654-5659.

Pillot, A. R., A. Guenole and J. M. Fournier (2002): Usefulness of $\mathrm{R} 72 \mathrm{H}$ PCR assay for differentiation between Vibrio parahaemolyticus and Vibrio alginolyicus species: validity by DNA-DNA hybridization. FEMS Microbiol. Lett., 215, $1-6$.

Sambrook, J., E. F. Fritsch and T. Maniatis (1989): Commonly used techniques in molecular cloning. In "Molecular cloning, $2^{\text {nd }}$ ed." Cold Spring Harbor Laboratory Press, New York, pp. E. 3-E. 4.

Simon K. Y. L., H. Z. Wang, H. W. L. Sheran, S. S. W. Rudolf and Y. C. K. Richard (2002): Analysis of the 16S23S rDNA intergenic spacers (IGSs) of marine vibrios for species-specific signature DNA sequences. Mar. Pollut. Bull., 44, 412-420.

Sung H. H., G. H. Kou and Y. L. Song (1993) Characterization of monoclonal antibodies and corresponding epitopes of Vibrio vulnificus. Fish Pathol., 28, 181-188.

Tajima, K., Y. Ezura and T. Kimura (1987): The possibility of use of a thermolabile antigen in detection of Vibrio anguillarum. (In Japanese English abstract) Fish Pathol., 22, 237-242.

Venkateswaran, K, N. Dohmoto and S. Harayama, (1998): Cloning and nucleotide sequence of the gyrB gene of Vibrio parahaemolyticus and its application in detection of this pathogen in shrimp. Appl. Environ. Microbiol., 64, 681687.

Warsen, A. E., M. J. Krug, S. LaFrentz, D. R. Stanek, F. J. Loge and D. R. Call (2004): Simultaneous discrimination between 15 fish pathogens by using $16 \mathrm{~S}$ ribosomal DNA PCR and DNA microarrays. Appl. Environ. Microbiol., 70, 4216-4221. 